Revista Brasileira de Farmacognosia Brazilian Journal of Pharmacognosy 21(5): 824-828, Sep./Oct. 2011

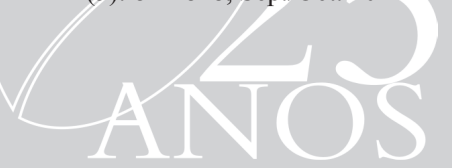

Article

Received 20 Dec 2010

Accepted 19 Jun 2011

Available online 26 Aug 2011

Keywords:

mexican Lupinus

phylogeny

quinolizidine alkaloid profiles

ISSN $0102-695 \mathrm{X}$

http://dx.doi.org/10.1590/S0102-

695X2011005000149

\section{Quinolizidine alkaloid composition in different organs of Lupinus aschenbornii}

\author{
Edith Montes Hernández, ${ }^{1}$ María L. Corona Rangel, ${ }^{1}$ Aidee \\ Encarnación Corona, ${ }^{1}$ Jorge A. Cantor del Angel, ${ }^{1}$ Jesús \\ Arnoldo Sánchez López, ${ }^{1}$ Frank Sporer, ${ }^{2}$ Michael Wink, ${ }^{2}$ Kalina \\ Bermúdez Torres ${ }^{*}, 1$
}

\author{
${ }^{I}$ Centro de Desarrollo de Productos Bióticos. Instituto Politécnico Nacional, \\ México, \\ ${ }^{2}$ Institute of Pharmacy \& Molecular Biotechnology, Heidelberg University, \\ Germany.
}

\begin{abstract}
Lupinus aschenbornii S. Schauer, Fabaceae, grows in the Central Highlands of Mexico, at altitudes between 2800 to $4300 \mathrm{~m}$ above sea level. The alkaloid patterns in organs of $L$. aschenbornii were analyzed by Gas-Liquid Chromatography-Mass Spectrometry (GLC-MS). Quinolizidine alkaloids (QA) were identified according to their mass fragmentation patterns, in combination with their Kovats retention indeces. Total QA content in organs differed substantially: seed contained $3.3 \mathrm{mg} / \mathrm{g}$ dry weight, flowers $2.8 \mathrm{mg} / \mathrm{g} \mathrm{DW}$, leaves $1.9 \mathrm{mg} / \mathrm{g} \mathrm{DW}$, stems $1.5 \mathrm{mg} / \mathrm{g} \mathrm{DW}$, and pods $1.4 \mathrm{mg} / \mathrm{g} \mathrm{DW}$. Roots do not accumulate QA and their profiles differed considerably: while seed stored $\mathrm{N}$-formylangustifoline (17\%), 17-oxolupanine (16\%), multiflorine (11\%) and an unidentified alkaloid (n.i.) 2869 $(11 \%)$ as main QA, sparteine was absent. In flowers, sparteine reached $73 \%$, in leaves up to $80 \%$, in stems up to $32 \%$ and in pods up to $96 \%$. Other QA present were lupanine (32\% in stem, $9 \%$ in flower and $7 \%$ in seed); $N$-formylangustifoline $(9 \%$ in stem and $4 \%$ in flower); multiflorine (6\% in stem and 3\% in flower). Differences in QA profile might be a strategy of lupins to avoid adaptation of possible predators because the different QA have different pharmacological properties.
\end{abstract}

\section{Introduction}

The genus Lupinus, Fabaceae, is widely distributed in the New World. About 230-350 species have been reported of which 200-320 occur in North and South America (Lewis et al., 2005). Mexico is a secondary diversification center; in the Mexican National Herbarium collection, our group found more than 100 species, however Sousa \& Delgado (1993) recognized only 65. Species delimitations in the genus Lupinus are poorly defined and their taxonomy needs a thorough revision.

Lupinus aschenbornii S. Schauer grows in the Central Highlands of Central America as part of the subalpine vegetation at altitudes between $2800 \mathrm{~m}$ and 4300 $\mathrm{m}$ above the sea level (Sousa \& Delgado, 1993; Stanley \& Steyermark, 1946). This species has several common names such as "frijolillo" and "cantuez". The plant is not known to be used by any local communities for food or medicine.

Many Lupinus species are characterized by the presence of quinolizidine alkaloids (QA) as part of a defense strategy against herbivores and microorganisms (Wink, 1992; 1983). QA profiles are rather constant within species but substantial variation is found in the alkaloid patterns of different organs (Wink, 1993b). More than 170 alkaloids of the quinolizidine group have been identified in different Lupinus species (Wink, 1993b; Wink, 1988). The main structural types of QA belong to the groups lupinine, sparteine/lupanine/multiflorine, $\alpha$-pyridone, matrine, Ormosia, piperidine and dipiperidine alkaloids (Wink, 1993a; Kinghorn \& Balandrin, 1984). Tetracyclic QA such as sparteine and lupanine are the major alkaloids present in almost all Lupinus species (Wink et al., 1995; Wink, 1993b). QA are constitutive metabolites; however their presence and abundance can vary during development and depends on plant organ (Zamora Natera et al., 2009; Cortes Sánchez et al., 2005; Wink, 1992). Some authors have shown that the QA profiles of North American species present a high degree of intraspecific variation (Wink \& Carey, 1994).

Bermúdez Torres et al. (1999) compared QA profiles of seeds and leaves of $L$. aschenbornii. They found that main QA of these organs are almost similar; both organs accumulate13 $\alpha$-hydroxylupanine (56 and $54.9 \%$, respectively) and an unidentified compound with 
a retention index RI 2849 (19.7 and 17.9\%, respectively); however angustifoline was detected only in seeds (18.9\%). As minor QA, a high diversity of QA-esters (less than 10\%) were found in seeds. Leaves contain tetrahydrorhombifoline $(8.07 \%), 13 \alpha$-tigloyloxilupanine (3.97\%), lupanine $(3.65 \%)$, and albine $(1,4 \%)$. On the other side, Bermúdez Torres et al. (2009) analyzed leaves of $L$. aschenbornii in order to evaluate its activity against Spodoptera frugiperda, they found sparteine as main QA $(85 \%)$ and lupanine, multiflorine and an unknown compound RI $1940(9.3 ; 3.3 ; 2.1 \%$, respectively) as minor QA. These results show that QA profiles differ in dependence of organ and probably origin. The aim of the present work was to evaluate QA composition in different organs (stems, leaves, flower, roots, pods and seeds) of $L$. aschenbornii plants in the same physiological state by Gas-liquid Chromatography-Mass Spectrometry (GLCMS). For L. aschenbornii, this is the first report of QA profile for the other organs than leaves.

\section{Materials and Methods}

\section{Plant material}

Ten plants of Lupinus aschenbornii S. Schauer, Fabaceae, were randomly collected in September 2009 from a single population of $L$. aschenbornii growing in La Joya, Iztaccihuatl Volcano, Estado de México, Mexico, $3800 \mathrm{~m}$ above sea level. All organs (root, leaf, stem and flower), except seeds and pods, were collected during the flowering stage. Seeds and pods were collected in October 2009. Plant material from each organ was ground and stored at room temperature in paper bags until use. Voucher specimens were deposited at the National Herbarium MEXU (Voucher No. 1297270, 1297311 and 1297317).

\section{Alkaloid extraction}

Alkaloids were extracted as described in Wink et al. (1995). Each organ (0.5 g) was homogenized separately in $20 \mathrm{~mL} 1 \mathrm{M} \mathrm{HCl}$. The homogenate was adjusted to $\mathrm{pH}$ 12 with a $3 \mathrm{M}$ aqueous solution of $\mathrm{NH}_{4} \mathrm{OH}$. Alkaloids were extracted by solid phase extraction using Extrelutcolumns $^{\circledR}$ and dichloromethane as eluent.

\section{Alkaloid identification by GLC-MS}

The alkaloid extracts were analyzed by GLCMS on a HP5890 instrument. The separation conditions were: column type: OV1; $30 \mathrm{~m}$; $0.25 \mathrm{~mm}$ i.d.; $0.25 \mu \mathrm{m}$ film thickness; Split ratio 1:30; carrier gas: He; flow $1 \mathrm{~mL}$ $\min ^{-1} ; 120{ }^{\circ} \mathrm{C} ; 2 \mathrm{~min}$ isothermal; $120-310^{\circ} \mathrm{C}$ at a rate of $4{ }^{\circ} \mathrm{C}$ min-1; then 4 min isothermal; the data system was started at $138^{\circ} \mathrm{C}$ oven temperature. The capillary column was directly coupled to a quadrupole mass spectrometer
(SSQ 7000, Thermo-Finnigan, Bremen, Germany). The injector temperature was $250^{\circ} \mathrm{C}$. Helium carrier gas flow rate was $2 \mathrm{~mL} / \mathrm{min}$. All the mass spectra were recorded with the following conditions: filament emission current, $100 \mathrm{~mA}$; electron energy, $70 \mathrm{eV}$; ion source, $175^{\circ} \mathrm{C}$.

The components were identified by their retention times, retention indices relative to $\mathrm{C} 9-\mathrm{C} 28$ $n$-alkanes, computer matching with the Wiley Registry of Mass Spectral Data $8^{\text {th }}$ edition, NIST Mass Spectral Library (December 2005) and the MS library at IPMB for alkaloids. Lupanine and sparteine were used as external standards for quantification.

\section{Results and Discussion}

GLC-MS separations of alkaloid extracts from seed, leaves, flowers and stems of L. aschenbornii are shown in Figure 1. Total Ion Chromatograms of pods and roots are not shown as for pods only two QA (sparteine and n.i. 2484) and for roots no QA were detected. It is evident that the presence and abundance of some individual QA varies in an organ-specific fashion. The diversity of QA is highest in seeds (11 QA) and in this organ relative abundances of individual QA are mostly equal, while QA diversity in leaves is poor, and sparteine is the predominant alkaloid. These results contrast with the observations of Planchuelo-Ravelo et al. (1993) and Wink (1992) that QA diversity is generally higher in green organs where QA are being synthesized. As seeds are the reproductions organ of plants, they have to be especially protected against predators to allow species survival; a higher diversity and concentration of defense compounds affords a wide range of protection.

As shown in Table 1, total QA content in organs differs substantially; seeds contain $3.3 \mathrm{mg}$ total QA/g DW, flowers $2.8 \mathrm{mg} / \mathrm{g}$ DW, leaves $1.9 \mathrm{mg} / \mathrm{g} \mathrm{DW}$, stems $1.5 \mathrm{mg} / \mathrm{g} \mathrm{DW}$, and pods $1.4 \mathrm{mg} / \mathrm{g} \mathrm{DW}$. These results confirm the assumption that QA are accumulated in the reproductive organs, and might play a role as part of the defense strategy against predators, but also contribute to $\mathrm{N}$ metabolism in these organs (Wink \& Witte, 1985).

While in seeds $N$-formylangustifoline, a tricyclic molecule is the main QA, the other evaluated organs contain mainly tetracyclic QA such as sparteine, lupanine and multiflorine. Seeds of L. aschenbornii are characterized by the presence of several QA esters (Bermúdez Torres, 2009; Bermúdez Torres, 1999), in this study we found $N$-formylangustifoline to be the main QA, at $17 \%$, and some other esters to be minor QA. However, European lupin species produce esters of 13-hydroxylupanine and hydroxymultiflorine mainly in shoots and leaves, but not in seeds (Wink et al., 1995). L. aschenbornii accumulates esters mostly in seeds. The results of the present study show that L. aschenbornii contains a similar QA pattern to other 

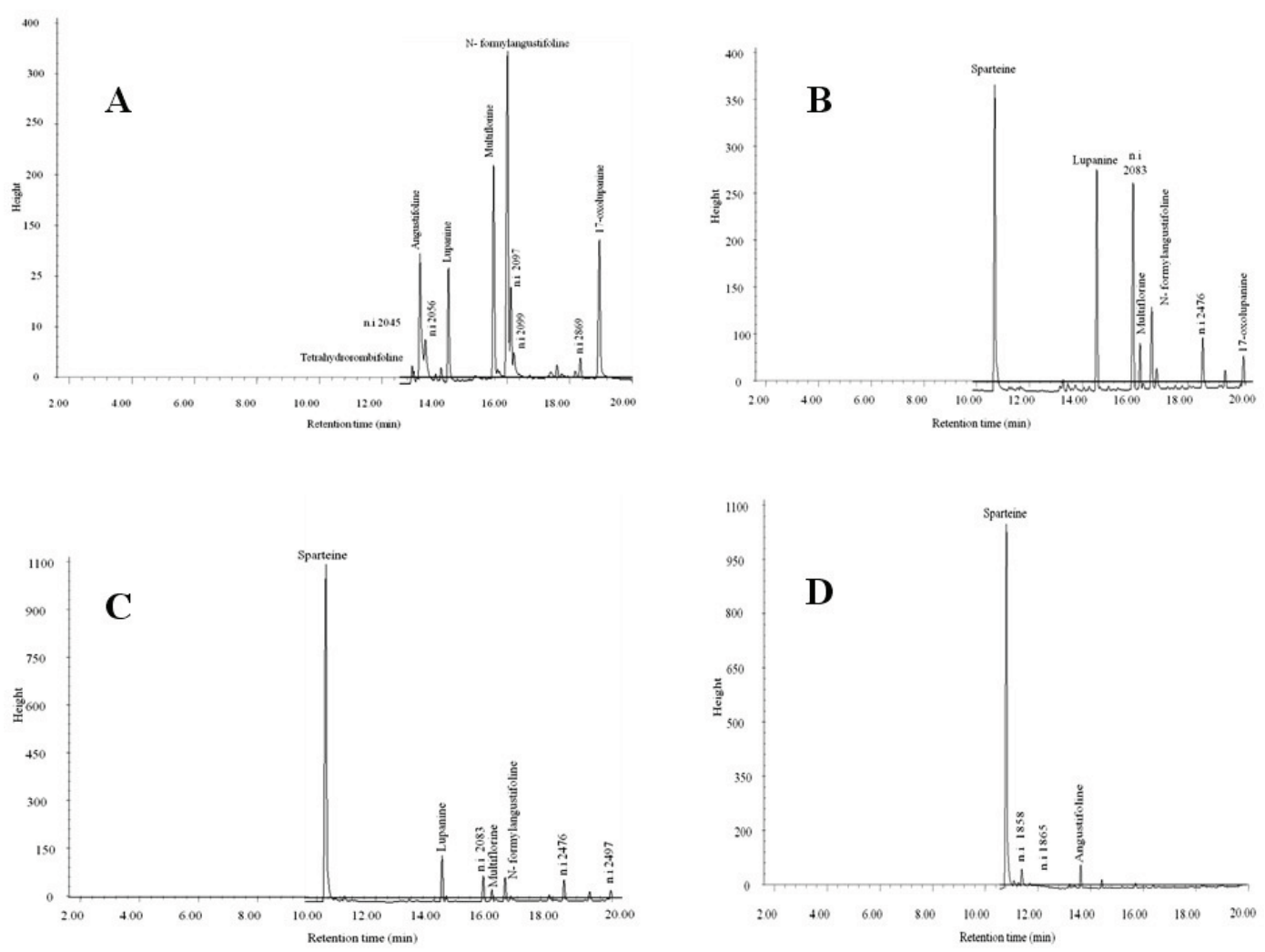

Figure 1. Chromatographic profile of seeds (A), stems (B), flowers (C), and leaves (D).

American species which are all closely related (Käss \& Wink, 1997). It is remarkable that there was no sparteine in seeds, a possible explanation is that during transport to this organ QA are transformed to QA esters and, finally, they will be accumulated in this way.

Table 1. Alkaloid composition in organs of L. aschenbornii.

\begin{tabular}{|c|c|c|c|c|c|c|c|}
\hline \multirow{2}{*}{$\mathrm{KI}$} & \multirow{2}{*}{ Alkaloid } & \multicolumn{6}{|c|}{ Alkaloid composition (\%) } \\
\hline & & Seed & Stem & Flower & Leaf & Pod & Root \\
\hline 1853 & sparteine & 0 & 32 & 73 & 80 & 96 & 0 \\
\hline 1858 & n.i. 1858 & 0 & 0 & 0 & 10 & 0 & 0 \\
\hline 1864 & n.i. 1864 & 0 & 0 & 0 & 5 & 0 & 0 \\
\hline 2039 & $\begin{array}{l}\text { tetrahydrorom- } \\
\text { bifoline }\end{array}$ & 3 & 0 & 0 & 0 & 0 & 0 \\
\hline 2046 & angustifoline & 2 & 0 & 0 & 5 & 0 & 0 \\
\hline 2056 & n.i. 2056 & 5 & 0 & 0 & 0 & 0 & 0 \\
\hline 2060 & lupanine & 7 & 19 & 9 & 0 & 0 & 0 \\
\hline 2085 & multiflorine & 11 & 6 & 3 & 0 & 0 & 0 \\
\hline 2095 & $\begin{array}{l}N \text {-formylangus- } \\
\text { tifoline }\end{array}$ & 17 & 9 & 4 & 0 & 0 & 0 \\
\hline 2097 & n.i. 2097 & 5 & 0 & 0 & 0 & 0 & 0 \\
\hline 2476 & n.i. 2476 & 0 & 7 & 4 & 0 & 0 & 0 \\
\hline 2484 & n.i. 2484 & 0 & 0 & 0 & 0 & 4 & 0 \\
\hline 2494 & 17-oxolupanine & 16 & 6 & 0 & 0 & 0 & 0 \\
\hline 2497 & n.i. 2497 & 0 & 0 & 3 & 0 & 0 & 0 \\
\hline 2869 & n.i. 2869 & 11 & 0 & 0 & 0 & 0 & 0 \\
\hline
\end{tabular}

KI: Kovat's Index; n.i.: not identified.
Sparteine and lupanine are the most widely distributed QA in the genus Lupinus (Wink et al., 1995). The major alkaloid in stem, flower, leaf and pod was sparteine $(32,73,80$ and $96 \%$, respectively). Wink et al. (1995) evaluated 56 species of the Old World, and the Americas; they found that almost half of the North American species contain sparteine as main QA. In relation to Mexican Lupinus species, Bermúdez Torres et al. (2009) reported sparteine as main QA in leaves of L. aschenbornii and L. montanus. Lupanine, another tetracyclic QA, was present in stem (19\%), flower (9\%) and seed (7\%) of L. aschenbornii. Multiflorine is one of the characteristic QA of seed (11\%), stem (6\%) and flower (3\%) of L. aschenbornii Schauer. Whereas sparteine, lupanine and their derivatives are very common in lupin species, multiflorine and their derivatives have a restricted distribution (Wink et al., 1995). They were found in Old World species such as L. albus, L. cosentinii, L. micranthus and L. varius and in South American species such as L. albescens and L. aureonitens (PlanchueloRavelo \& Wink, 1993; Planchuelo-Ravelo et al., 1993). Traces of this alkaloid were also found in some North American species (Wink et al., 1995).

Table 2 presents the mass spectral characteristics of individual QA (alkaloid name, Kovat's retention index, molecular ion $\mathrm{M}+$, significant fragment ions and their relative abundance). Fifteen QA were detected in the extracts and seven were identified unequivocally by 
comparing their retention index and informative mass spectra with those in the data bases. Eight QA could not be identified; some of them are main QA (Table 1), and according to their mass spectra some are QA esters.

With these results it is obvious that profiles differ between organs, however we are currently not able to explain such diversity in the alkaloid composition between organs of L. aschenbornii, although some possibilities merit consideration and discussion: i) Structural changes of QA usually imply differences in their pharmacological and toxicological properties (Schmeller et al., 1994). The difference in QA profiles in the organs evaluated might be a measure to reduce predator adaptation. "One predator, one organ" might be a defense strategy that would confer Lupinus the possibility to survive and reproduce in an adverse environment. This means that each predator would be adapted to specific QA profiles and their intrinsic pharmacological properties, only being able to feed on the respective organ; ii) Other possible explanations for the variation of QA profiles in organs could be an uneven transport of QA through the plant. The leaf is the organ of QA biosynthesis; a higher QA diversity should be expected in this organ. However, in the population studied, leaves had fewer QA than other organs, maybe because they are transported to various organs necessary for the survival of the plant (Wink, 1985). Flowers and seeds are the reproductive organs, so a survival strategy for the species might be to accumulate higher amounts of QA, on the one hand as defense against predators but also as a $\mathrm{N}$ source for seedlings to provide amino acids and proteins (Wink \& Witte, 1985). Stem (and specially the phloem) is the organ for the translocation of QA; therefore we should find here QA in a form that can be transported.
QA have been suggested to be of use as chemotaxonomical markers. However the results of this work show that QA profiles vary dramatically between organs, and as shown in other studies, also between developing stages (Wink, 1992). More importantly, QA profiles do not match lupin phylogeny and it has been assumed that a patchy distribution results from differential gene regulation (Wink et al., 2010). Another question which should be discussed, is the observation that published QA profiles of L. aschenbornii (Bermúdez Torres et al., 2009; Bermúdez Torres et al., 1999), differ considerably: How can this phenomenon be explained?

i. The first but least likely explanation could be that plants were collected in different physiological stages. As shown by other authors (Wink 1992; ZamoraNatera et al., 2009) QA levels might vary during plant development.

ii. Alkaloid profiles are ultimately the result of chemical warfare between the plant and herbivores (Adler \& Kittelson, 2004), and the presence and abundance of QA-inducing predators may be influenced by ambient factors such as the season.

iii. L. aschenbornii like all North American Lupinus species is phylogenetically a young species (Käss \& Wink, 1997), and its traits are still evolving. Another possibility should be that species limits are not well defined for L. aschenbornii and that the presently recognized taxon is in reality a species complex. Or hybridization with a population of L. montanus growing very close to it, may have influenced the QA of $L$. aschenbornii.

To try to respond all these questions, we plan to pursue the chemical and molecular characterization of individuals of this population, to evaluate inter population variability of QA profiles and genetic variation.

Table 2. Quinolizidine alkaloids identified in L. aschenbornii by GLC-MS.

\begin{tabular}{|c|c|c|c|c|c|c|c|}
\hline \multirow{2}{*}{$\begin{array}{l}\text { Alkaloid } \\
\text { Angustifoline }\end{array}$} & \multirow{2}{*}{$\frac{\mathrm{KI}}{2046}$} & \multirow{2}{*}{$\frac{\mathrm{M}^{+}}{234}$} & \multicolumn{5}{|c|}{ Characteristics ions (abundance \%) } \\
\hline & & & $193(100)$ & $112(85)$ & $150(15)$ & $55(20)$ & $94(11)$ \\
\hline Sparteine & 1853 & 234 & $137(100)$ & $98(90)$ & $234(44)$ & $193(25)$ & $84(10)$ \\
\hline n.i. 1858 & 1858 & 254 & $135(100)$ & $149(75)$ & $107(58)$ & $121(52)$ & $191(25)$ \\
\hline n.i. 1865 & 1865 & 282 & $135(100)$ & $121(53)$ & 107(39) & $149(35)$ & $220(25)$ \\
\hline Tetrahydrorombifoline & 2039 & 248 & $207(100)$ & $58(80)$ & $112(15)$ & $108(10)$ & $248(1)$ \\
\hline n.i. 2056 & 2056 & 394 & $272(100)$ & $137(31)$ & $273(28)$ & $127(25)$ & $82(23)$ \\
\hline Lupanine & 2060 & 248 & $136(100)$ & $149(60)$ & $248(40)$ & $150(34)$ & $219(8)$ \\
\hline Multiflorine & 2085 & 246 & $134(100)$ & $246(65)$ & $148(20)$ & $110(15)$ & $217(5)$ \\
\hline N-Formylangustifoline & 2095 & 262 & $112(100)$ & 193(98) & $221(41)$ & $262(2)$ & $150(19)$ \\
\hline n.i. 2097 & 2097 & 366 & $272(100)$ & $207(23)$ & 273(18) & $136(14)$ & $57(15)$ \\
\hline n.i. 2476 & 2476 & 294 & $245(100)$ & $112(83)$ & $263(43)$ & $55(36)$ & $149(35)$ \\
\hline n.i. 2484 & 2484 & 284 & $246(100)$ & $134(56)$ & $55(44)$ & $112(30)$ & $148(23)$ \\
\hline 17-Oxolupanine & 2494 & 262 & $150(100)$ & $262(40)$ & $110(30)$ & $234(10)$ & $55(20)$ \\
\hline n.i. 2493 & 2493 & 282 & $245(100)$ & $112(83)$ & $263(50)$ & $55(35)$ & $149(34)$ \\
\hline n.i. 2869 & 2869 & 282 & $245(100)$ & $112(80)$ & $203(53)$ & $149(35)$ & $55(33)$ \\
\hline
\end{tabular}




\section{Acknowledgments}

This work was funded by the Secretaría de Investigación y Posgrado del Instituto Politécnico Nacional (SIP 20090435 and 20100688) and by CONACYT (100808). E. Montes Hernández and J. Cantor del Angel are indebted to Instituto Politécnico Nacional (PIFI-IPN) and CONACYT for the fellowship awarded. A. Encarnación Corona thanks CONACYT for support. K. Bermúdez Torres thanks EDI and SIBE-IPN for support. Astrid Backhaus provided valuable help at the IPMB (Heidelberg). We thank Peter Winterton and Luc Legal for valuable help on reviewing the manuscript.

\section{References}

Adler S, Kittelson M. 2004. Variation in Lupinus arboreus alkaloid profiles and relationships with multiple herbivores. Biochem Sis Ecol 32: 371-390.

Bermúdez Torres K, Martínez H J, Figueroa-Brito R, Wink M, Legal L 2009. Activity of quinolizidine alkaloids from three Mexican Lupinus against lepidopteran crop pest Spodoptera frugiperda. Biocontrol 54: 459-466.

Bermúdez-Torres K, Robledo-Quintos NR, Martínez-Herrera J, Te, Wink M 1999. Patrón de acumulación de alcaloides en hojas y semillas de Lupinus aschenbornii crecidos en México. Rev Latinoamericana Quim 27: 101-105.

Cortés-Sánchez M, Altares P, Pedrosa MM, Burbano C, Cuadrado C, Goyoaga C, Muzquiz M, JiménezMartínez C, Dávila-Ortiz G 2005. Alkaloid variation during germination in different lupin species. Food Chem 90: 347-335.

Käss E, Wink M 1997. Molecular Phylogeny and phylogeography of the genus Lupinus (family Leguminosae) inferred from nucleotide sequences of the RbcL Gene and ITS 1+2 sequences of rDNA. Plant Syst Evol 208: 139-167.

Kinghorn AD, Balandrin MF 1984. Quinolizidine alkaloids of the Leguminosae: structural types, analysis, chemotaxonomy, and biological activities. In Pelletier WS (ed) Alkaloids: chemical and biological perspectives. New York: Wiley, p. 105-148.

Lewis GP, Schrire B, Mackinder B, Lock M 2005. Legumes of the World. Kew: Royal Botanic Gardens.

Planchuelo-Ravelo AM, Wink M 1993. Alkaloid composition of Lupinus albescens (Fabaceae) from South America. Z Naturforsch 48c: 414-416.

Planchuelo-Ravelo AM, Witte L, Wink M 1993. Quinolizidine alkaloid profiles of South American lupins: Lupinus linearis and the Lupinus gibertianus complex. $Z$ Naturforsch 48c: 702-706.

Schmeller T, Sauerwein M, Sporer F, Müller WE, Wink M 1994 Binding of quinolizidine alkaloids to nicotinic and muscarinic receptors. J Nat Products 57: 1316-1319.

Stanley PC, Steyermark JA 1946. Lupinus. In Flora of
Guatemala. Feldiana Botany, vol. 24, part. V., p. 287290.

Sousa SM, Delgado SA 1993. Mexican Leguminosae: phytogeography, endemism, and origins. In Ramamoorthy T, Bye R, Lot A, Fa J (eds.) Biological diversity of Mexico: origins and distribution. New York: Oxford Univ. Press, p. 459-511.

Wink M, Botschen F, Gosmann C, Schäfer H, Waterman PG 2010. Chemotaxonomy seen from a phylogenetic perspective and evolution of secondary metabolism. In Wink $\mathrm{M}$ (ed.) Biochemistry of plant secondary metabolism. Blackwell: Annual Plant Reviews, vol. 40, 2 ed, p. 364-433.

Wink M, Meissner C, Witte L 1995. Pattern of quinolizidine alkaloid in 56 species of the genus Lupinus. Phytochemistry 38: 139-153.

Wink M 1983. Wounding-induced increase of quinolizidine alkaloids accumulation in lupin leaves. Z Naturforsch 38c: 905-909.

Wink M, Witte L 1985. Quinolizidine alkaloids as nitrogen source for lupin seedlings and cell suspension cultures. Z Naturforsch 40c: 767-775.

Wink M 1985. Metabolism of quinolizidine alkaloids in plants and cell suspension cultures: Induction and degradation. In Neumann KH, Barz W, Reinhard E (eds.) Primary and secondary metabolism of plants and cell cultures. Berlin: Springer Verlag, p. 107-116.

Wink M 1988. Plant breeding: importance of plant secondary metabolites for protection against pathogens and herbivores. Theor Appl Genetics 75: 225-233.

Wink M 1992. The role of quinolizidine alkaloids in plant insect interactions. In Bernays EA (ed.) Insect-plants interactions. Boca Raton: CRC Press, p. 133-169.

Wink M 1993a. Quinolizidine alkaloids. In Waterman PG (ed.) Methods in plant biochemistry. London: Academic Press, p. 197-239.

Wink M 1993b. Allelochemical properties and the raison d'être of alkaloids. In Cordell G (ed.) The Alkaloids. Academic press, vol. 43, p. 1-118.

Zamora-Natera F, García-López P, Ruiz-López M, RodríguezMacías R, Salcedo-Pérez E 2009. Composición y concentración de alcaloides en Lupinus exaltatus Zucc. durante su crecimiento y desarrollo. Interciencia 34: 672-676

\section{*Correspondence}

Kalina Bermúdez Torres

Centro de Desarrollo de Productos Bióticos. Instituto Politécnico Nacional

Apartado Postal 24, C.P. 62731, Yautepec-Morelos, México

kbermudes@ipn.mx

Tel.: +55 57296000 Ext. 82520

Fax: +55 57296000 Ext. 85252 